University of Nebraska - Lincoln

DigitalCommons@University of Nebraska - Lincoln

Court Review: The Journal of the American

Judges Association

American Judges Association

2014

Should the Science of Adolescent Brain Development Inform

Public Policy?

Laurence Steinberg

Temple University, Ids@temple.edu

Follow this and additional works at: https://digitalcommons.unl.edu/ajacourtreview

Steinberg, Laurence, "Should the Science of Adolescent Brain Development Inform Public Policy?" (2014). Court Review: The Journal of the American Judges Association. 492.

https://digitalcommons.unl.edu/ajacourtreview/492

This Article is brought to you for free and open access by the American Judges Association at DigitalCommons@University of Nebraska - Lincoln. It has been accepted for inclusion in Court Review: The Journal of the American Judges Association by an authorized administrator of DigitalCommons@University of Nebraska -

Lincoln. 


\section{Should the Science of Adolescent Brain Development Inform Public Policy?}

Laurence Steinberg

$\mathbf{T}$ The science of adolescent brain development is making its way into the national conversation. As an early researcher in the field, I regularly receive calls from journalists asking how the science of adolescent brain development should affect the way society treats teenagers. I have been asked whether this science justifies raising the driving age, outlawing the solitary confinement of incarcerated juveniles, excluding 18-year-olds from the military, or prohibiting 16-year-olds from serving as lifeguards on the Jersey Shore. Explicit reference to the neuroscience of adolescence is slowly creeping into legal and policy discussions as well as popular culture. The U.S. Supreme Court discussed adolescent brain science during oral arguments in Roper $v$. Simmons, ${ }^{1}$ which abolished the juvenile death penalty, and cited the field in its 2010 decision in Graham v. Florida, ${ }^{2}$ which prohibited the sentencing of juveniles convicted of crimes other than homicide to life without parole.

There is now incontrovertible evidence that adolescence is a period of significant changes in brain structure and function. Although most of this work has appeared just in the past 15 years, there is already strong consensus among developmental neuroscientists about the nature of these changes. And the most important conclusion to emerge from recent research is that important changes in brain anatomy and activity take place far longer into development than had been previously thought. Reasonable people may disagree about what these findings may mean as society decides how to treat young people, but there is little room for disagreement about the fact that adolescence is a period of substantial brain maturation with respect to both structure and function.

\section{BRAIN CHANGES}

There are four noteworthy, structural changes in the brain during adolescence. First, there is a decrease in gray matter in prefrontal regions of the brain, reflective of synaptic pruning, the process through which unused connections between neurons are eliminated. The elimination of these unused synapses occurs mainly during pre-adolescence and early adolescence, when major improvements in basic cognitive abilities and logical reasoning are seen, in part due to these very anatomical changes.
Second, important changes in activity involving the neurotransmitter dopamine occur during early adolescence, especially around puberty. There are substantial changes in the density and distribution of dopamine receptors in pathways that connect the limbic system and prefrontal cortex. The limbic system is associated with emotions, rewards, and punishments, and the prefrontal cortex is the brain's chief executive officer. There is more dopaminergic activity in the pathways that connect the two during the first part of adolescence than at any other time in development. Because dopamine plays a critical role in how humans experience pleasure, these changes have important implications for sensation-seeking.

Third, there is an increase in the strength of connections between the prefrontal cortex and the limbic system. If you were to compare a young teenager's brain with that of a young adult, you would see a much more extensive network of myelinated cables connecting brain regions. This anatomical change is especially important for emotion regulation, which is facilitated by increased connectivity between regions important in the processing of emotional information and those important in self-control. These connections permit different brain systems to communicate with each other more effectively, and these gains are also ongoing well into late adolescence.

Fourth, there is an increase in white matter in the prefrontal cortex during adolescence. This is largely the result of myelination, the process through which nerve fibers become sheathed in myelin, a white, fatty substance that improves the efficiency of brain circuits. Unlike the synaptic pruning of the prefrontal areas, which is mainly finished by mid-adolescence, myelination continues well into late adolescence and early adulthood. This increased efficiency in neural connections within the prefrontal cortex is important for higher-order cognitive functions-planning ahead, weighing risks and rewards, and making complicated decisions, among others-that are regulated by multiple prefrontal areas working in concert.

Adolescence is not just a time of tremendous change in the brain's structure. It is also a time of important changes in how the brain works, as revealed in studies using functional magnetic resonance imaging, or fMRI. What do these imaging studies reveal about the adolescent brain? First, over the course of adolescence and into early adulthood, there is a
Reprinted and adapted with permission by the University of Texas at Dallas, Richardson, TX. Originally published as Laurence Steinberg, Should the Science of Adolescent Brain Development Inform Public Policy?, 28(3) Issues in SCIENCE AND TeChNology 67 (Spring 2012).

\section{Footnotes}

1. 543 U.S. 551 (2005).

2. 560 U.S. 48 (2010). 
strengthening of activity in brain systems involving self-regulation. During tasks that require self-control, adults employ a wider network of brain regions than do adolescents, and this trait may make self-control easier, by distributing the work across multiple areas of the brain rather than overtaxing a smaller number of regions.

Second, there are important changes in the way the brain responds to rewards. When one examines brain scans of individuals who are shown rewarding stimuli, such as piles of coins or pictures of happy faces, adolescents' reward centers are usually activated more than children's or adults' brains. (Interestingly, these age differences are more consistently observed when individuals are anticipating rewards than when they are receiving them.) Heightened sensitivity to anticipated rewards motivates adolescents to engage in risky acts when the potential for pleasure is high, such as with unprotected sex, fast driving, or experimentation with drugs. In our laboratory, Jason Chein and I have shown that this hypersensitivity to reward is particularly pronounced when adolescents are with their friends, and we think this helps explain why adolescent risk-taking so often occurs in groups. ${ }^{3}$

A third change in brain function over the course of adolescence involves increases in the simultaneous involvement of multiple brain regions in response to arousing stimuli, such as pictures of angry or terrified faces. Before adulthood, there is less cross-talk between the brain systems that regulate rational decision-making and those that regulate emotional arousal. During adolescence, very strong feelings are less likely to be modulated by the involvement of brain regions involved in controlling impulses, planning ahead, and comparing the costs and benefits of alternative courses of action. This is one reason why susceptibility to peer pressure declines as adolescents grow into adulthood; as they mature, individuals become better able to put the brakes on an impulse that is aroused by their friends.

\section{IMPORTANCE OF TIMING}

These structural and functional changes do not all take place along one uniform timetable, and the differences in their timing raise two important points relevant to the use of neuroscience in public policy. First, there is no simple answer to the question of when an adolescent brain becomes an adult brain. Brain systems implicated in basic cognitive processes reach adult levels of maturity by mid-adolescence, whereas those that are active in self-regulation do not fully mature until late adolescence or even early adulthood. In other words, adolescents mature intellectually before they mature socially or emotionally, a fact that helps explain why teenagers who are so smart in some respects sometimes do surprisingly dumb things.

To the extent that society wishes to use developmental neuroscience to inform public policy decisions on where to draw age boundaries between adolescence and adulthood, it is important to match the policy question with the right science. In his dissenting opinion in Roper, the juvenile-death-penalty case, Justice Antonin Scalia criticized the American Psychological Association, which submitted an amicus brief arguing that adolescents are not as mature as adults and therefore should not be eligible for the death penalty. As Scalia pointed out, the association had previously taken the stance that adolescents should be permitted to make decisions about abortion without involving their parents, because young people's decision-making is just as competent as that of adults.

The association's two positions may seem inconsistent at first glance, but it is entirely possible that an adolescent might be mature enough for some decisions but not others. After all, the circumstances under which individuals make medical decisions and commit crimes are very different and make different sorts of demands on their brains and abilities. State laws governing adolescent abortion require a waiting period before the procedure can be performed, as well as consultation with an adult—a parent, health care provider, or judge. These policies discourage impetuous and shortsighted acts and create circumstances under which adolescents have been shown to be just as competent at making decisions as adults. In contrast, violent crimes are usually committed by adolescents when they are emotionally aroused and with their friends-two conditions that increase the likelihood of impulsivity and sensationseeking and that exacerbate adolescent immaturity. From a neuroscientific standpoint, it therefore makes perfect sense to have a lower age for autonomous medical decision-making than for eligibility for capital punishment, because certain brain systems mature earlier than others.

There is another kind of asynchrony in brain development during adolescence that is important for public policy. Middle adolescence is a period during which brain systems implicated in how a person responds to rewards are at their height of arousability but systems important for self-regulation are still immature. The different timetables followed by these different brain systems create a vulnerability to risky and reckless behavior that is greater in middle adolescence than before or after. It's as if the brain's accelerator is pressed to the floor before a good braking system is in place. Given this, it is no surprise that criminal activity peaks around age 17-as does first experimentation with alcohol and marijuana, automobile crashes, accidental drownings, and attempted suicide.

In sum, the consensus emerging from recent research on the adolescent brain is that teenagers are not as mature as adults in either brain structure or function. This does not mean that adolescents' brains are "defective," just as newborns' muscular systems, which do not allow them to walk, or language systems, which do not allow them to carry on conversations, are

3. Jason Chein et al., Peers Increase Adolescent Risk Taking by Enhancing Activity in the Brain's Reward Circuitry, 14(2) Developmental SCI. F1(2011). 


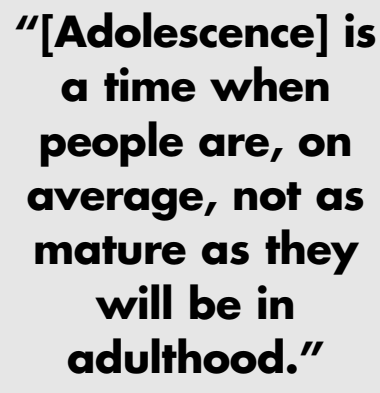

not defective. The fact that the adolescent brain is still developing, and in this regard is less mature than the adult brain, is normative, not pathological. Adolescence is a developmental stage, not a disease, mental illness, or defect. But it is a time when people are, on average, not as mature as they will be in adulthood.

I am frequently asked how to reconcile this view of adolescence with historical evidence that adolescents successfully performed adult roles in previous eras. This may be true, but all societies in recorded history have recognized a period of development between childhood and adulthood, and writers as far back as Aristotle have characterized adolescents as less able to control themselves and more prone to risk-taking than adults. In 1623 (without the benefit of brain scans), Shakespeare wrote in The Winter's Tale: "I would there were no age between ten and three-and-twenty, or that youth would sleep out the rest; for there is nothing in the between but getting wenches with child, wronging the ancientry, stealing, fighting."

\section{SCIENCE IN THE POLICY ARENA}

Although there is a good degree of consensus among neuroscientists about many of the ways in which brain structure and function change during adolescence, it is less clear just how informative this work is about adolescent behavior for public policy. Because all behavior must have neurobiological underpinnings, it is hardly revelatory to say that adolescents behave the way they do because of "something in their brain." Moreover, society hardly needs neuroscience to tell it that, relative to adults, adolescents are more likely to engage in sensation seeking, less likely to control their impulses, or less likely to plan ahead. So how does neuroscience add to society's understanding of adolescent behavior? What is the value, other than advances in basic neuroscience, of studies that provide neurobiological evidence that is consistent with what is already known about human behavior?

I will consider five such possibilities, two that I think are valid, two that I think are mistaken, and one where my assessment is equivocal. Let me begin with two rationales that are widely believed but that are specious.

The first mistake is to interpret age differences in brain structure or function as conclusive evidence that certain behaviors must be hard-wired. A correlation between brain development and behavioral development is just that: a correlation. It says nothing about the causes of the behavior or about the relative contributions of nature and nurture. In some cases, the behavior may indeed follow directly from biologically driven changes in brain structure or function. But in others, the reverse is true-that is, the observed brain change is the consequence of experience. Yes, adolescents may develop better impulse control as a result of changes within the prefrontal cortex, and it may be true that these anatomical changes are programmed to unfold along a predetermined timetable. But it is also plausible that the structural changes observed in the prefrontal cortex result from experiences that demand that adolescents exercise self-control, in much the same way that changes in muscle structure and function often follow from exercise.

A second mistake is assuming that the existence of a biological correlate of some behavior demonstrates that the behavior cannot be changed. It is surely the case that some of the changes in brain structure and function that take place during adolescence are relatively impervious to environmental influence. But the brain is malleable, and there is a good deal of evidence that adolescence is, in fact, a period of especially heightened neuroplasticity. That's one reason it is a period of such vulnerability to many forms of mental illness.

I suspect that the changes in reward sensitivity that I described earlier are largely determined by biology and, in particular, by puberty. I say this because the changes in reward seeking observed in young adolescents are also seen in other mammals when they go through puberty. This makes perfect sense from an evolutionary perspective because adolescence is the period during which mammals become sexually active, a behavior that is motivated by the expectation of pleasure. An increase in reward sensitivity soon after puberty is added insurance that mammals will do what it takes to reproduce while they are at the peak of fertility, including engaging in a certain amount of risky behavior, such as leaving the nest or troop to venture out into the wild. In fact, the age at peak human fecundity (that is, the age at which an individual should begin having sex if he or she wants to have the most children possible) is about the same as the age at the peak of risk-taking-between 16 and 17 years of age.

Other brain changes that take place during adolescence are probably driven to a great extent by nurture and may therefore be modifiable by experience. There is growing evidence that the actual structure of prefrontal regions active in self-control can be influenced by training and practice. So in addition to assuming that biology causes behavior, and not the reverse, it is also a mistake to think that the biology of the brain cannot be changed.

\section{HOW SCIENCE CAN HELP}

How, then, does neuroscience contribute to a better understanding of adolescent behavior? As I said, I think the neuroscience serves at least two important functions.

First, neuroscientific evidence can provide added support for behavioral evidence when the neuroscience and the behavioral science are conceptually and theoretically aligned. Notice that I used the word "support" here. When neuroscientific findings about adolescent brain development are consistent with findings from behavioral research, the neuroscience provides added confidence in the behavioral findings; scientific evidence of any sort is always more compelling when it has been shown to be valid. But it is incorrect to privilege the neuroscientific evidence over the behavioral evidence, which is frequently done because the neuroscientific evidence is often incorrectly assumed to be more reliable, precise, or valid. Many nonscientists are more persuaded by neuroscience than by behavioral science, because they often lack the training or expertise that would enable them to view the neuroscience through a critical lens. In science, familiarity breeds skepticism, and the lack of knowledge that most laypersons have 
about the workings of the brain, much less the nuances of neuroscientific methods, often leads them to be overly impressed by brain science and underwhelmed by behavioral research, even when the latter may be more relevant to policy decisions.

A second way in which neuroscience can be useful is that it may help generate new hypotheses about adolescent development that can then be tested in behavioral studies. This is especially important when behavioral methods cannot be used to test alternative accounts of a phenomenon. Let me illustrate this point with an example from our ongoing research.

As I noted earlier, it has been hypothesized that heightened risk-taking in adolescence is thought to be the product of an easily aroused reward system and an immature self-regulatory system. The arousal of the reward system takes place early in adolescence and is closely tied to puberty, whereas the maturation of the self-regulatory system is independent of puberty and unfolds gradually, from preadolescence through young adulthood.

In our studies, we have shown that reward sensitivity, preference for immediate rewards, sensation-seeking, and a greater focus on the rewards of a risky choice all increase between preadolescence and mid-adolescence, peak between ages 15 and 17 , and then decline. ${ }^{4}$ In contrast, controlling impulses, planning ahead, and resisting peer influence all increase gradually from pre-adolescence through late adolescence, and in some instances, into early adulthood.

Although one can show without the benefit of neuroscience that the inclination to take risks is generally higher in adolescence than before or after, having knowledge about the course of brain development provides insight into the underlying processes that might account for this pattern. We've shown in several experiments that adolescents take more risks when they are with their friends than when they are alone. But is this because the presence of peers interferes with self-control or because it affects the way in which adolescents experience the rewards of the risky decision? It isn't possible to answer this question by asking teenagers why they take more risks when their friends are around. They admit that they do, but they say they do not know why. But through neuroimaging, we discovered that the peer effect was specifically due to the impact that peers have on adolescents' reward sensitivity. Why does this matter? Because if the chief reason that adolescents experiment with tobacco, alcohol, and other drugs is that they are at a point in life where everything rewarding feels especially so, trying to teach them to "Just Say No" is probably futile. I have argued elsewhere that raising the price of cigarettes and alcohol, thereby making these rewarding substances harder to obtain, is probably a more effective public policy than health education. ${ }^{5}$

I have now described two valid reasons to use neuroscience to better understand adolescent behavior and two questionable ones. I want to add a fifth, which concerns the attributions we make about individuals' behavior. This particular use of neuroscience is having a tremendous impact on criminal law.

A few years ago I was asked to provide an expert opinion in a Michigan case involving a prison inmate named Anthony, who as a 17-year-old was part of a group of teenagers who robbed a small store. During the robbery, one of the teenagers shot and killed the storekeeper. Although the teenagers had planned the robbery, they did not engage in the act with the intention of shooting, much less murdering, someone. But under the state's criminal law, the crime qualified as felony murder, which in Michigan carries a mandatory sentence of life without the possibility of parole for all members of the group involved in the robbery-including Anthony, who had fled the store before the shooting took place.

Anthony-who has been in prison for 33 years-requested that his sentence be vacated in light of the Supreme Court's ruling in Graham v. Florida that life without parole is cruel and unusual punishment for juveniles because they are less mature than adults. ${ }^{6}$ The ruling in that case was limited to crimes other than homicide, so Anthony's challenge was based on the argument that the logic behind the Graham decision applies to felony murder as well.

I was asked specifically whether a 17-year-old could have anticipated that someone might be killed during the robbery. It is quite clear from the trial transcript that Anthony didn't anticipate this consequence, but "didn't" is not the same as "couldn't." It is known from behavioral research that the average 17-year-old is less likely than the average adult to think ahead, control his impulses, and foresee the consequences of his actions, and clinical evaluations of Anthony revealed that he was a normal 17-year-old. But "less likely" means just that; it doesn't mean "unable," but neither does it mean "unwilling." As I will explain, the distinction between "didn't" and "couldn't" is important under the law. And studies of adolescent brain development might be helpful in distinguishing between the two.

The issue was not whether Anthony is guilty. He freely admitted having participated in the robbery, and there was clear evidence that the victim was shot and killed by one of the robbers. But even when someone is guilty, many factors can influence the sentence he receives. Individuals who are deemed less than fully responsible are punished less severely than those who are judged to be fully responsible, even if the
4. E.g., Chein et al, supra note 3; Laurence Steinberg, A Social Neuroscience Perspective on Adolescent Risk-Taking, 28 DeVELOPMENTAL REv. 78-106; Laurence Steinberg, et al., Age Differences in Sensation Seeking and Impulsivity as Indexed by Behavior and Self-Report: Evidence for a Dual Systems Model, 44 Developmental Psychol. 1764 (2008).
5. Laurence Steinberg, Risk Taking in Adolescence: What Changes, and Why?, 1021 Annals N.Y. ACAD. SCI. 51 (2004).

6. See also Miller v. Alabama, 132 S. Ct. 2455 (2012) (even for the crime of murder, mandatory sentences of life without the possibility of parole are unconstitutional). 


"... I have
argued that
adolescents
should be viewed
as inherently
less responsible
than adults and
should be
punished less
harshly than
adults, even
when their
crimes are
identical."

consequences of the act are identical. For example, manslaughter is not punished as harshly as premeditated murder, even though both result in the death of another individual. So the question in Anthony's case, as it was in the Roper and Graham Supreme Court cases, was whether 17-year-olds are fully responsible for their behavior. If they are not, they should not be punished as severely as individuals whose responsibility is not diminished.

In order for something to diminish criminal responsibility, it has to be something that was not the person's fault-that was outside his control. If someone has an untreatable tumor on his frontal lobe that is thought to make him unable to control aggressive outbursts, he is less than fully responsible for his aggressive behavior, and the presence of the tumor would be viewed as a mitigating factor if he were being sentenced for a violent crime. On the other hand, if someone with no neurobiological deficit goes into a bar, drinks himself into a state of rage, and commits a violent crime as a result, the fact that he was drunk does not diminish his responsibility for his act. It doesn't matter whether the mitigating factor is biological, psychological, or environmental. The issue is whether the diminished responsibility is the person's fault and whether the individual could have been able to compensate for whatever it is that was uncontrollable.

Judgments about mitigation are often difficult to make because most of the time, factors that diminish responsibility fall somewhere between the extremes of things that are obviously beyond an individual's control, such as brain tumors, and those that an individual could have controlled, such as self-inflicted inebriation. In many cases, things are not clearcut. One must make a judgment call, and one looks for evidence that tips the balance in one direction or the other. Profound mental retardation that compromises foresight is a mitigating condition. A lack of foresight as a result of stupidity that is within the normal range of intelligence is not. Being forced to commit a crime because a gun is pointed at one's head mitigates criminal responsibility. Committing a crime in order to save face in front of friends who have made a dare does not. Many things can lead a person to act impulsively or without foresight but are not necessarily mitigating. A genetic inclination toward aggression is probably in this category, as is having been raised in a rotten neighborhood. Both are external forces, but society does not see them as so determinative that they automatically diminish personal responsibility.
As I have argued elsewhere, ${ }^{7}$ studies of adolescent brain anatomy clearly indicate that regions of the brain that regulate such things as foresight, impulse control, and resistance to peer pressure are still developing at age 17. Imaging studies show that immaturity in these regions is linked to adolescents' poorer performance on tasks that require these capabilities. There is evidence that the adolescent brain is less mature than the adult brain in ways that affect some of the behaviors that mitigate criminal responsibility. This suggests that at least some of adolescents' irresponsible behavior is not entirely their fault.

The brain science, in and of itself, does not carry the day, but when the results of behavioral science are added to the mix, I think it tips the balance toward viewing adolescent impulsivity, short-sightedness, and susceptibility to peer pressure as developmentally normative phenomena that teenagers cannot fully control. This is why I have argued that adolescents should be viewed as inherently less responsible than adults and should be punished less harshly than adults, even when their crimes are identical. ${ }^{8}$ I do not find persuasive the counterargument that some adolescents can exercise self-control or that some adults are just as impulsive and shortsighted as teenagers. Of course there is variability in brain function and behavior among adolescents, and of course there is variability among adults. But the average differences between the age groups are significant, and that is what counts as society draws age boundaries under the law on the basis of science.

\section{AGE RANGES FOR RESPONSIBILITY}

Beyond criminal law, how should social policy involving young people take this into account? Society needs to distinguish between people who are ready for the rights and responsibilities of adulthood and those who are not. Science can help in deciding where best to draw the lines. Based on what is now known about brain development-and I say "now known" because new studies are appearing every month-it is reasonable to posit that there is an age range during which adult neurobiological maturity is reached. Framing this as an age range, rather than pinpointing a discrete chronological age, is useful because doing so accommodates the fact that different brain systems mature along different timetables, and different individuals mature at different ages and rates. The lower bound of this age range is probably somewhere around 15, and the upper bound is probably somewhere around 22. By this I mean that if society had an agreed-upon measure of adult neurobiological maturity (which it doesn't yet have but may at some point in the future), it would be unlikely that many normally developing individuals would have attained this mark before turning 15 and would have failed to reach it by age 22 .

If society were to choose either of these endpoints as the age of majority, it would be forced to accept many errors of classification because granting adult status at age 15 would result in treating many immature individuals as adults, which is dan-
7. Laurence Steinberg, Should the Science of Adolescent Brain Development Inform Public Policy?, 64 Am. Psychologist 739 (2009).

8. Elizabeth S. Scott \& Laurence Steinberg, Rethinking JuvEnILE JusTICE (2008); Elizabeth Cauffman \& Laurence Steinberg, (Im)matu- rity of Judgment in Adolescence: Why Adolescents May Be Less Culpable than Adults, 18 BeHAv. SCI. \& L. 741 (2000); Laurence Steinberg, Adolescent Development and Juvenile Justice, 5 AnN. Rev. CLinICAL PsyCHOL. 47 (2009). 
gerous, whereas waiting until age 22 would result in treating many mature individuals as children, which is unjust. So what is society to do? I think there are four possible options.

The first option is to pick the mid-point of this range. Yes, this would result in classifying some immature individuals as adults and some mature ones as children. But this would be true no matter what chronological age is picked, and assuming that the age of neurobiological maturity is normally distributed, fewer errors would be made by picking an age near the middle of the range than at either of the extremes. Doing so would place the dividing line somewhere around 18, which, it turns out, is the presumptive age of majority pretty much everywhere around the world. In the vast majority of countries, 18 is the age at which individuals are permitted to vote, drink, drive, and enjoy other adult rights. And just think-the international community arrived at this without the benefit of brain scans.

A second possibility would be to decide, on an issue-byissue basis, what it takes to be "mature enough." Society does this regularly. Although the presumptive age of majority in the United States is 18 , the nation deviates from this age more often than not. Consider, for a moment, the different ages mandated for determining when individuals can make independent medical decisions, drive, hold various types of employment, marry, view R-rated movies without an adult chaperone, vote, serve in the military, enter into contracts, buy cigarettes, and purchase alcohol. The age of majority with respect to these matters ranges from 15 to 21 , which is surprisingly reasonable, given what science says about brain development. The only deviation I can think of that falls out of this range is the nation's inexplicable willingness to try people younger than 15 as adults, but this policy, in part because of the influence of brain science, is now being questioned in many jurisdictions.

Although the aforementioned age range may be reasonable, society doesn't rely on science to link specific ages to specific rights or responsibilities, and some of the nation's laws are baffling, to say the least, when viewed through the lens of science or public health. How is it possible to rationalize permitting teenagers to drive before they are permitted to see R-rated movies on their own, sentencing juveniles to life without parole before they are old enough to serve on a jury, or sending young people into combat before they can buy beer? The answer is that policies that distinguish between adolescents and adults are made for all sorts of reasons, and science, including neuroscience, is only one of many proper considerations.

A third possibility would be to shift from a binary classification system, in which everyone is legally either a child or an adult, to a regime that uses three legal categories: one for children, one for adolescents, and one for adults. The nation does this for some purposes under the law now, although the age boundaries around the middle category aren't necessarily scientifically derived. For example, many states have graduated drivers' licensing, a system in which adolescents are permitted to drive but are not granted full driving privileges until they reach a certain age. This model also is used in the construction of child labor laws, where adolescents are allowed to work once they've reached a certain age, but there are limits on the types of jobs they can hold and the numbers of hours they can work.

In our book, Rethinking Juvenile Justice, ${ }^{9}$ Elizabeth Scott and I have argued that this is how the nation should structure the justice system, treating adolescent offenders as an intermediate category, neither as children, whose crimes society excuses, nor as adults, whom society holds fully responsible for their acts. While there are some areas of the law where a three-way system would be difficult to imagine, such as voting, it has been suggested that society should apply this model to other areas of the law. For example, we could permit individuals between 18 and 20 to purchase beer and wine, but not hard liquor, and implement especially stiff punishment for adolescents who become intoxicated or engage in wrongdoing under the influence of alcohol.

A final possibility is acknowledging that there is variability in brain and behavioral development among people of the same chronological age and making individualized decisions, rather than drawing categorical age boundaries at all. Many of the Supreme Court justices who dissented in the juveniledeath-penalty and life-without-parole cases took this stance. They argued that instead of treating adolescents as a class of individuals who are too immature to be held fully responsible for their behavior, the policy should be to assess each offender's maturity to determine his criminal culpability. The justices did not specify what tools would be needed to do this, however, and reliably assessing psychological maturity is easier said than done. There is a big difference between using neuroscience to guide the formulation of policy and using it to determine how individual cases are adjudicated. Although it may be possible to say that, on average, people who are Johnny's age are typically less mature than adults, we cannot say whether Johnny himself is.

Science may someday have the tools to image an adolescent's brain and draw conclusions about that individual's neurobiological maturity relative to established age norms for various aspects of brain structure and function, but such norms do not yet exist, and the cost of doing individualized assessments of neurobiological maturity would be prohibitively expensive. Moreover, it is not clear that society would end up making better decisions using neurobiological assessments than those it makes on the basis of chronological age or than

9. Supra note 8 . 
those it might make using behavioral or psychological measures. It makes far more sense to rely on a driving test than a brain scan to determine whether someone is ready to drive. So don't expect to see brain scanners any time soon at your local taverns or movie theaters.

\section{ACCEPTING THE CHALLENGES}

The study of adolescent brain development has made tremendous progress in the very short period that scientists have been studying the adolescent brain systematically. As the science moves ahead, the big challenge facing those of us who want to apply this research to policy will be in understanding the complicated interplay of biological maturation and environmental influence as they jointly shape adolescent behavior. And this can be achieved only through collaboration between neuroscientists and scholars from other disciplines. Brain science should inform the nation's policy discussions when it is relevant, but society should not make policy decisions on the basis of brain science alone.

Whether the revelation that the adolescent brain may be less mature than scientists had previously thought is ultimately a good thing, a bad thing, or a mixed blessing for young people remains to be seen. Some policymakers will use this evidence to argue in favor of restricting adolescents' rights, and others will use it to advocate for policies that protect adolescents from harm. In either case, scientists should welcome the opportunity to inform policy discussions with the best available empirical evidence.

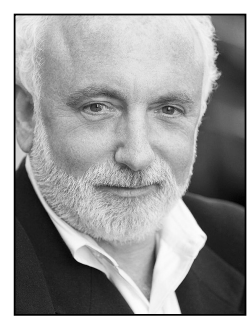

Laurence Steinberg, Ph.D., is the Distinguished University Professor of Psychology at Temple University. Dr. Steinberg is the former Director of the MacArthur Foundation Research Network on Adolescent Development and Juvenile Justice, and a member of the MacArthur Foundation Research Network on Law and Neuroscience. An internationally recognized expert on psychological development during adolescence, Dr. Steinberg was the lead scientist in the preparation of the American Psychological Association's amicus briefs submitted to the U.S. Supreme Court in Roper v. Simmons, Graham v. Florida, and Miller v. Alabama. He is the author of approximately 350 articles and 18 books on growth and development during the teenage years. He is a Fellow of the American Academy of Arts and Sciences.Email: lds@temple.edu 